\title{
Gradhiva
}

GRADHI

Revue d'anthropologie et d'histoire des arts

$33 \mid 2022$

Wampum : les perles de la diplomatie

\section{Je mets encore un mot sur ce collier}

Manuscrits anonymes rédigés vers 1726, présentés par Benjamin Balloy

Benjamin Balloy

\section{OpenEdition}

\section{Journals}

Édition électronique

URL : https://journals.openedition.org/gradhiva/6167

DOI : 10.4000/gradhiva.6167

ISSN : 1760-849X

Traduction(s) :

I Shall Add One More Word to this Belt - URL : https://journals.openedition.org/gradhiva/6273 [en]

Éditeur

Musée du quai Branly Jacques Chirac

Édition imprimée

Date de publication : 2 février 2022

Pagination : 144-157

ISBN : 978-2-35744-133-0

ISSN : 0764-8928

Référence électronique

Benjamin Balloy, " Je mets encore un mot sur ce collier », Gradhiva [En ligne], 33 | 2022, mis en ligne le 02 février 2022, consulté le 15 septembre 2022. URL : http://journals.openedition.org/gradhiva/6167 ; DOI : https://doi.org/10.4000/gradhiva.6167 


\section{Je mets encore}

un mot sur ce collier

Les deux documents qu'on présente ici proviennent de reliquats de saisies révolutionnaires, rassemblés sous le Second Empire avec d'autres rapports manuscrits relatifs au ministère de la Marine du début du règne de Louis XV. La première pièce est un mémoire anonyme, concernant les usages et les modalités de fabrication des perles wampum, ou «porcelaines», rédigé vers 1726, vraisemblablement en France et à la demande des autorités. S'y trouve intégré le texte d'un second mémoire, transmis par un correspondant, également anonyme, depuis la «Nouvelle Yorck». Le second document est une transcription des «paroles» ou discours prononcés par au moins deux orateurs iroquois anonymes devant le marquis de Beauharnois à Montréal en 1726. Ce dernier accueillait la délégation des Iroquois des cinq villages et celle des chrétiens de la mission voisine du Sault-Saint-Louis, en qualité de gouverneur de la Nouvelle-France, succédant au défunt marquis de Vaudreuil.

À chacune des parties du discours adressé au représentant du roi («Louis mon Père qui m'a toujours aimé», fo 39) correspond l'ostension et le transfert d'un «collier» ou wampum, chargé d'en articuler plus spécifiquement le sens. De nombreux autres exemplaires de ces discours, transcrits et conservés dans les Archives nationales, attestent de l'attention 
prêtée par les Français à cette forme. Derrière le style orné de la transcription, on perçoit toutefois la voix de l'orateur, et une conception iroquoise de l'efficacité du discours scandé par des «colliers», à travers notamment des métaphores dont les anthropologues ont pu montrer le formalisme cohérent.

Pris ensemble, ces deux documents offrent une vue complémentaire des façons dont les Français ont largement appréhendé ce type d'artefacts, caractérisations que n'auraient pas forcément partagées les Amérindiens producteurs de ces paroles: d'un côté, l'effort pour conceptualiser la diversité apparente des fonctions remplies dans les contextes autochtones (monnaie diplomatique, parure, symbole d'engagement, mémoire des traités, matérialisation d'articles ou de clauses, etc.); de l'autre, l'intégration des wampums dans les pratiques diplomatiques des Français, et notamment les pratiques d'écriture, depuis le $x V_{I I}$ e siècle. Car, voilà en définitive l'implicite: les wampums seraient une forme d'écriture inaboutie et inefficace. Les transcriptions diplomatiques, tout en signalant la structure par «collier» du discours, restent beaucoup mieux archivées que les colliers éventuellement transmis avec, attestant de cette conception ambivalente. L'analogie souvent avancée avec le document écrit - transmettant de façon impersonnelle mais stable un contenu d'information - et présumée évidente n'est peut-être qu'un trompe-l'œil; elle passe en tout cas largement à côté de la dimension étroitement personnelle du lien qui s'établit entre la parole et les wampums. Ramener les wampums à une parole matérialisée laisserait alors dans l'ombre une diversité de rapports plus riches entre l'objet et l'énoncé.

Plutôt que de faire du wampum une représentation dérivée ou la simple mimesis d'une parole, ne faut-il pas aussi tenir compte de ce que les wampums - assemblés, montrés, suspendus à une corde, déposés, conservés - font à la parole ? S'interroger sur le type d'instrument de parole qu'ils sont, sur le type d'efficacité dont ils sont crédités, c'est s'interroger sur le cadre d'interaction que le wampum et la parole instituent conjointement. Les métaphores iroquoises - essuyer les yeux, nettoyer la natte, habiller le défunt, ouvrir le gosier, entretenir le chemin... - énoncent peut-être réellement ce qu'elles effectuent? C'est finalement la nature des relations négociées entre ceux qui se trouvent ainsi reliés - allocutaires, énonciateurs, communautés représentées, tiers évoqués, morts et vivants qui reste largement à analyser. 


\section{Mémoire concernant les colliers de porcelaine des Sauvages, leurs différents usages, et la matière dont ils sont composés.}

Manuscrit anonyme rédigé vraisemblablement à Paris, vers 1725.

Tiré de: Recueil de pièces diverses, la plupart relatives à I'histoire de la première moitié du règne de Louis XV. V-VIII Marine et Colonies (1667-1735). Paris, BnF. Département des Manuscrits. NAF 2550, f. 24 r à 27 r. 


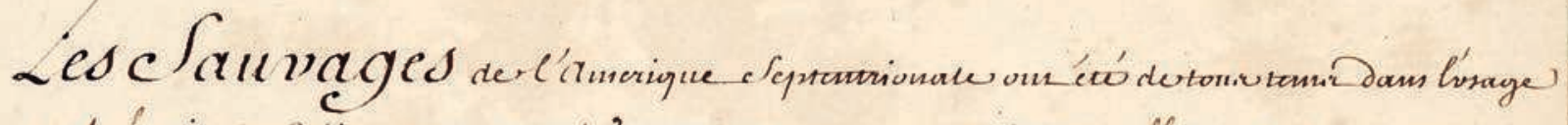

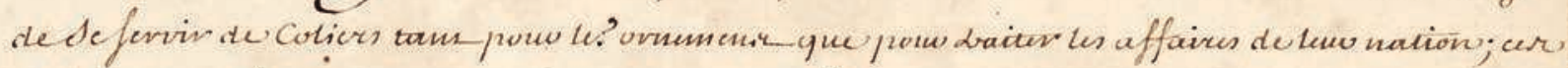

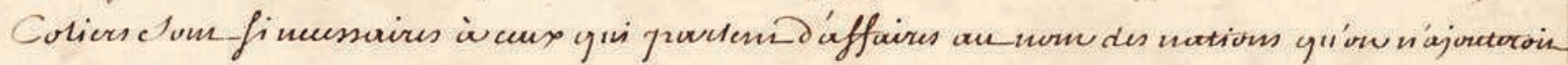

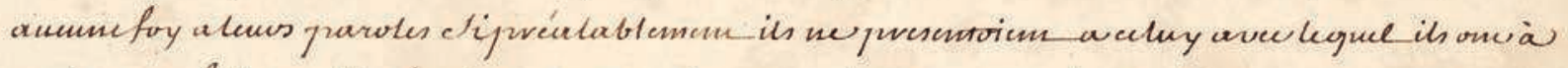

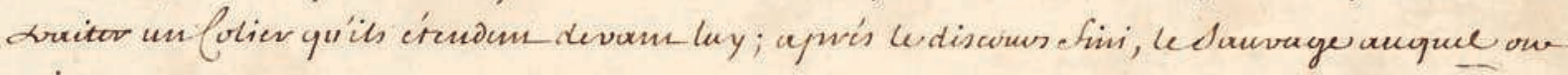

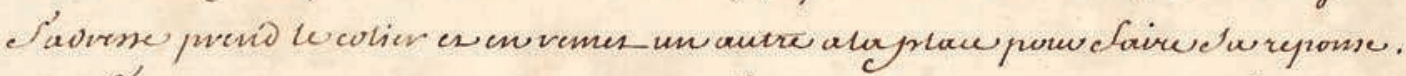

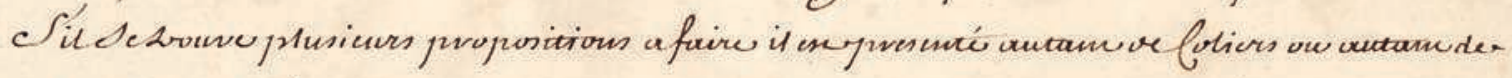
brunctues de proccetuines.

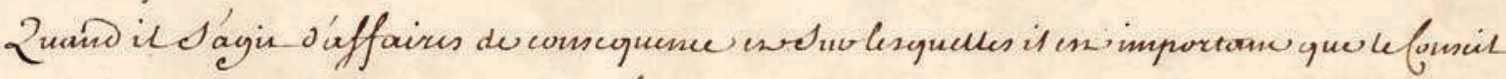

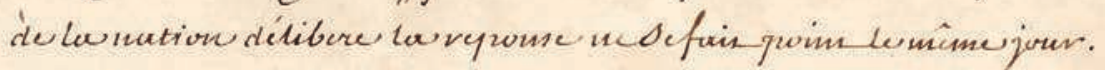

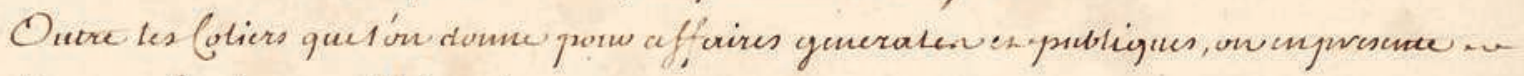

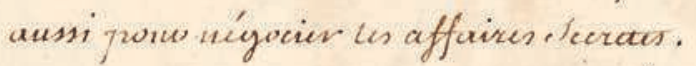

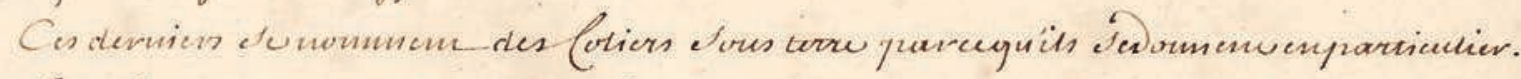

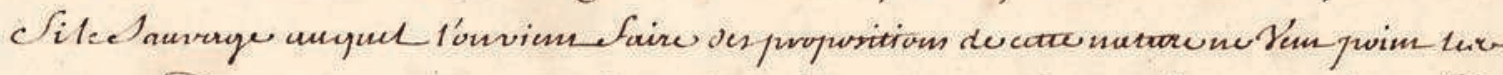

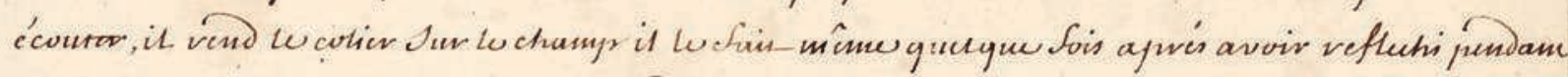

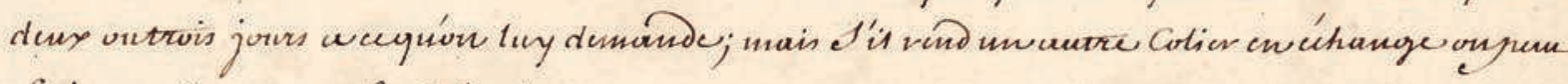

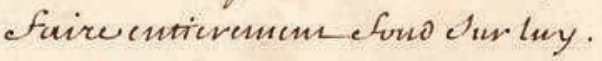

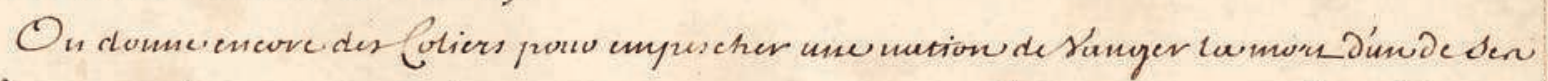

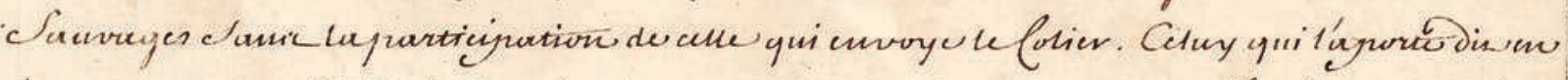

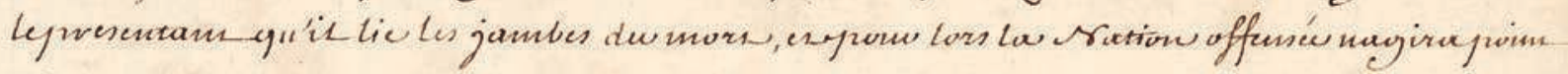
Cum mavertir alle qui a unryú we Colier.

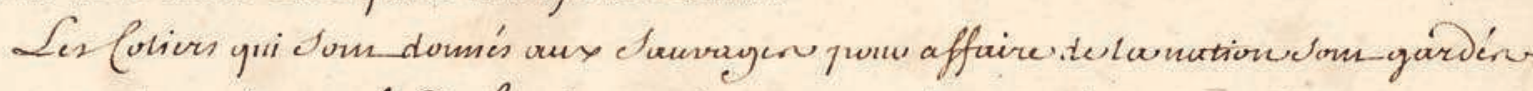

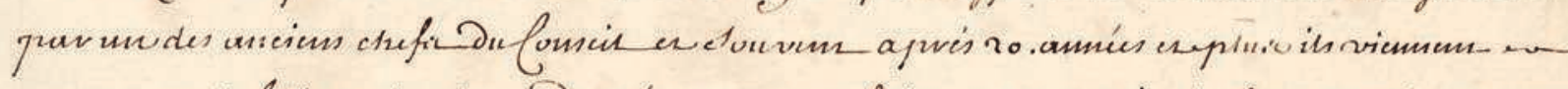

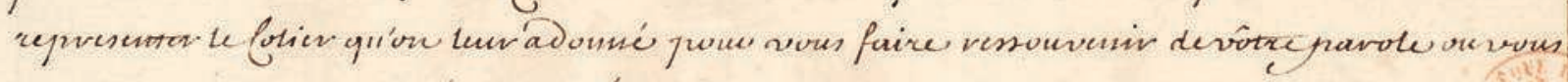
reprocher yicerew y avés mumyué.

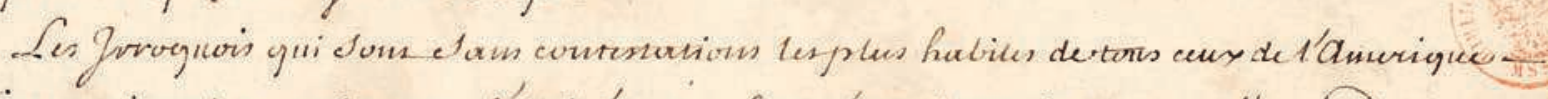

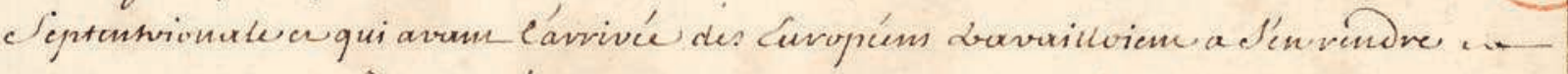

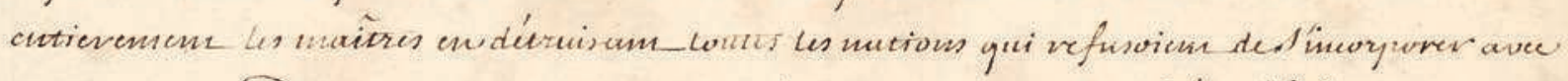

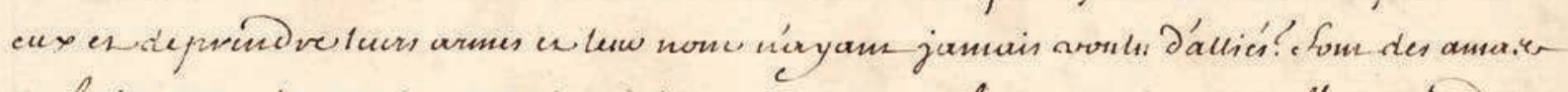

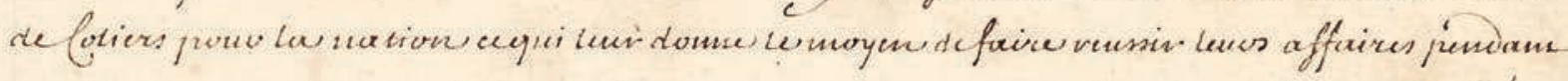

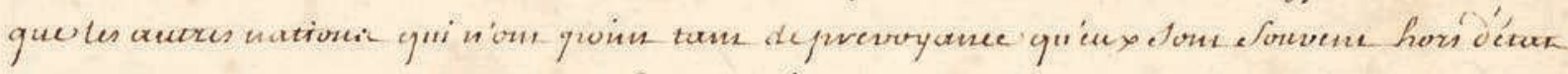

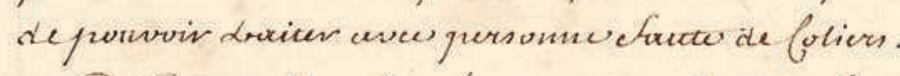

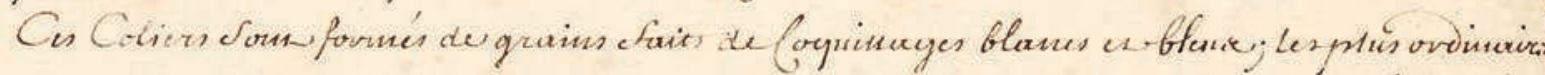

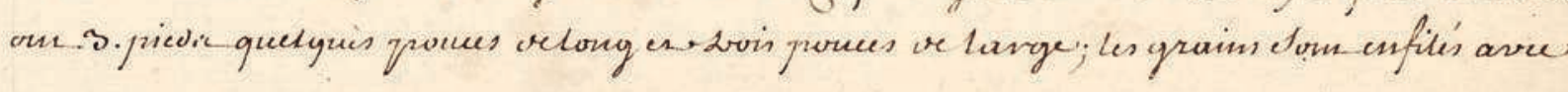




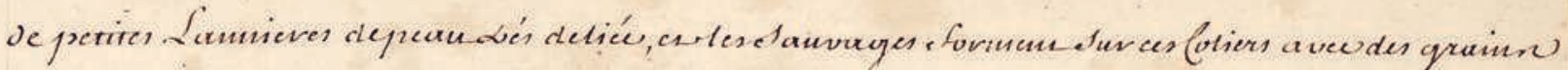

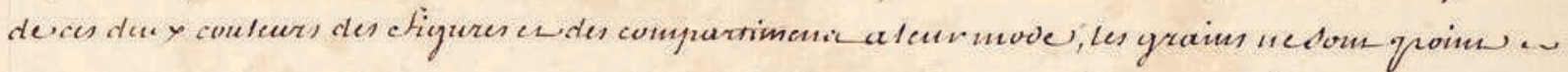

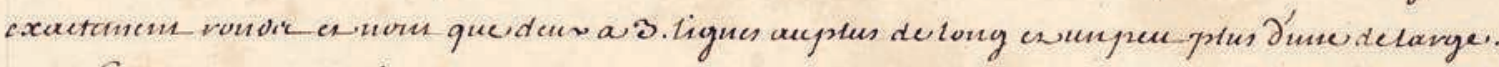

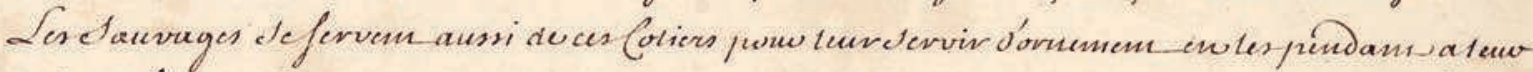

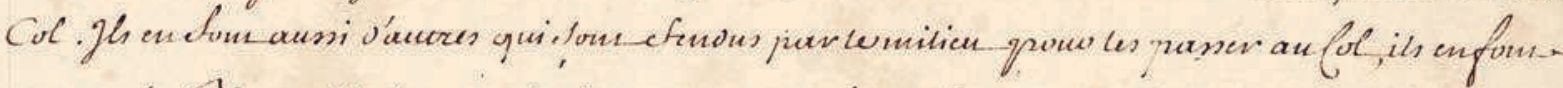

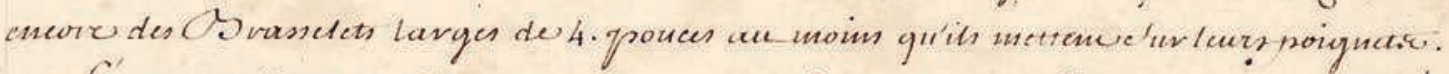

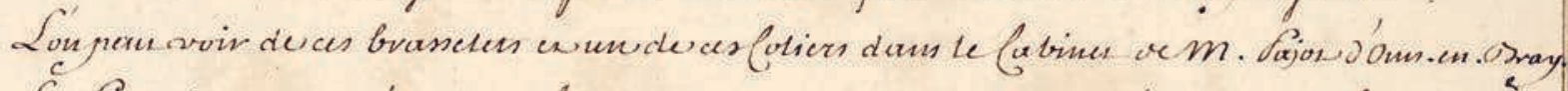

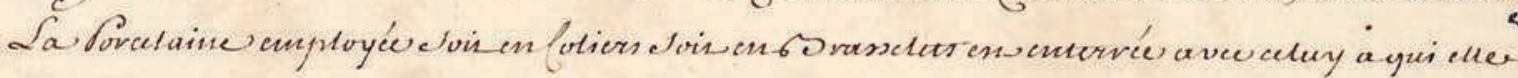
a)furatenoin.
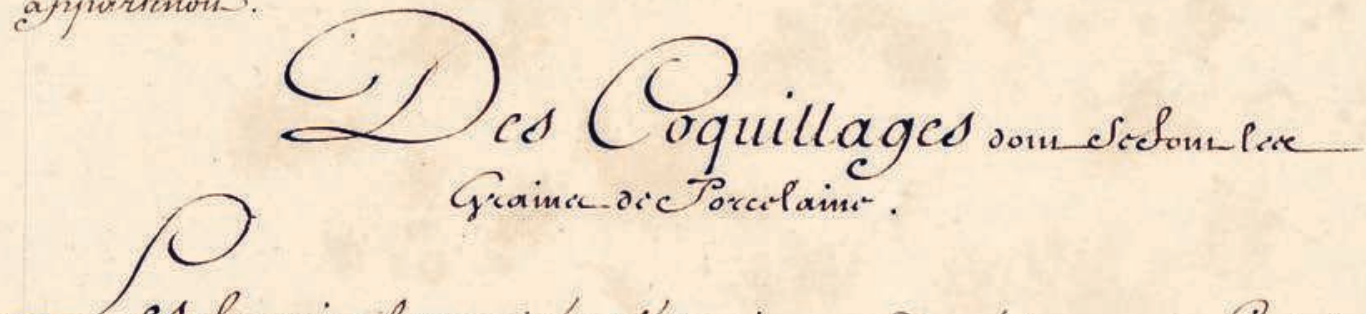

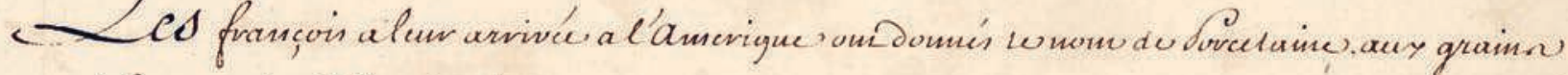
qui, formenit les Coliers des taurages.

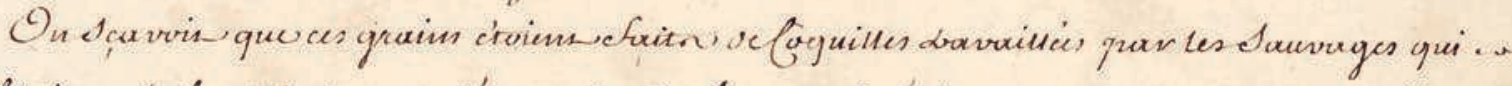

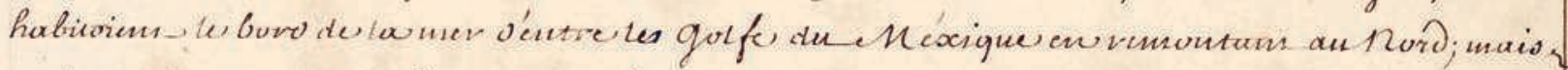

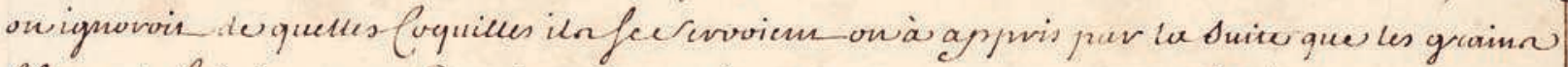

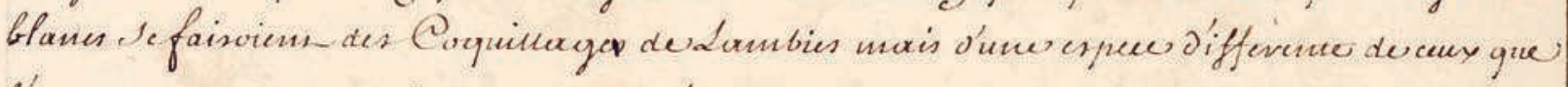

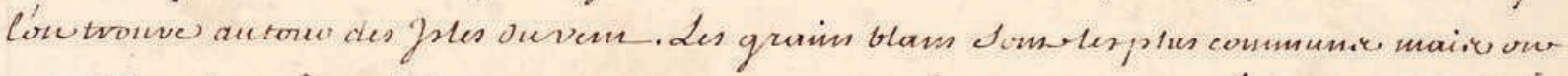

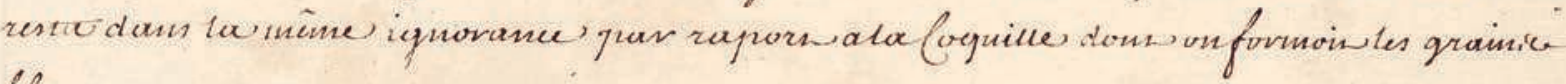
Glues.

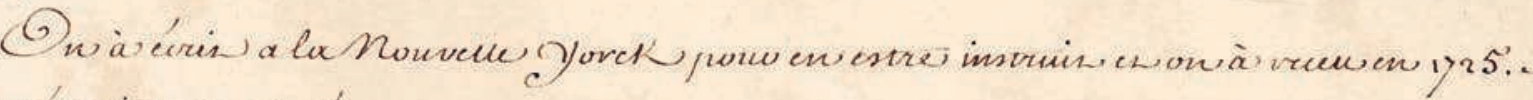
Lemémoinc cy uywós.

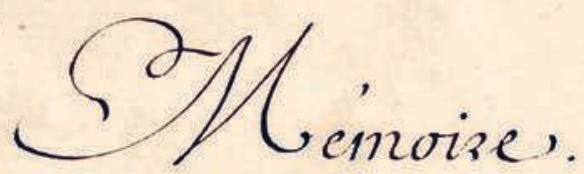

$\operatorname{Lot}_{01}^{2}$

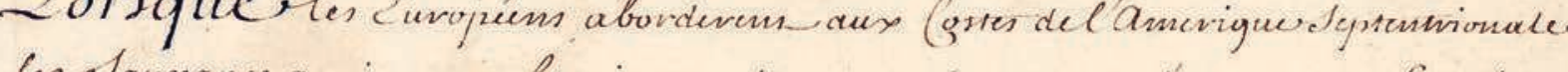

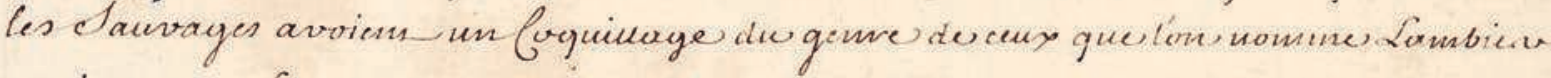

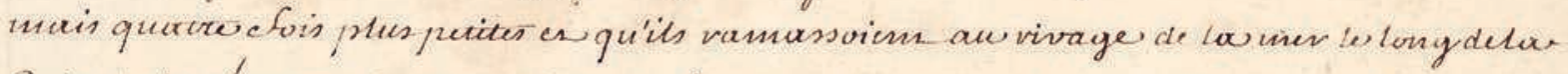

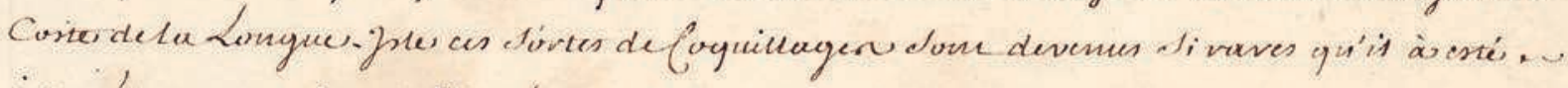
jusquéa presens innzussible ón avoir.

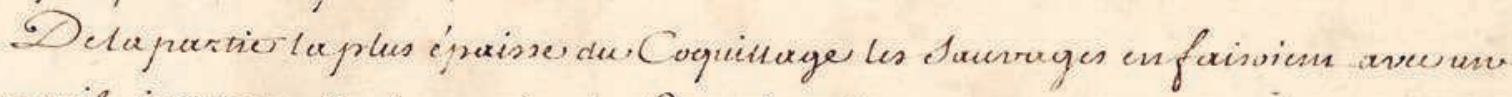

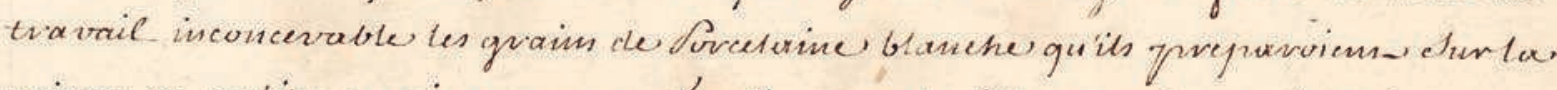

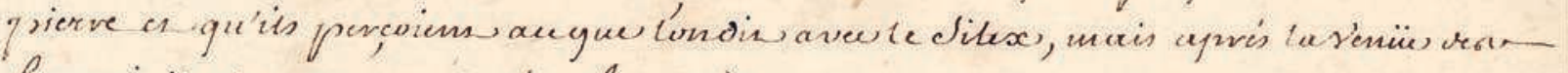

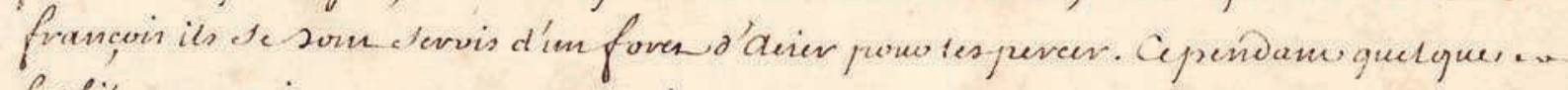

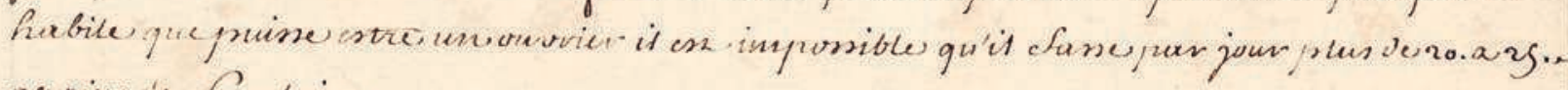
graxins des orationes.

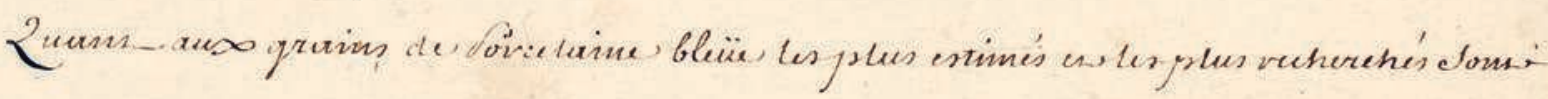




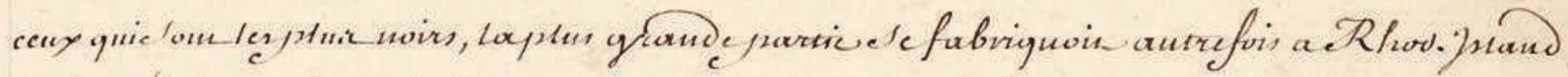

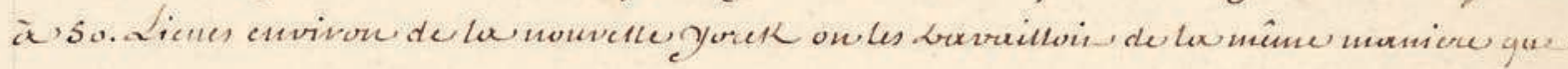

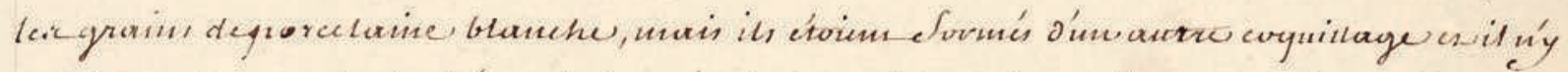

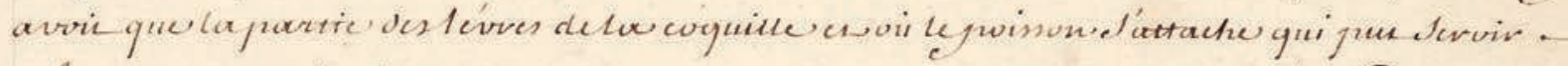

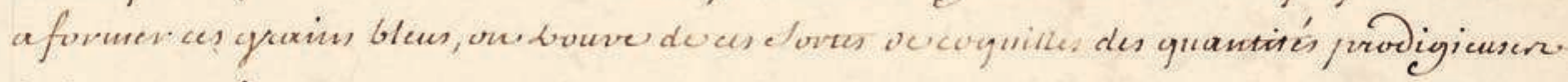
Le long des cîtes de ter nouvere yorck.

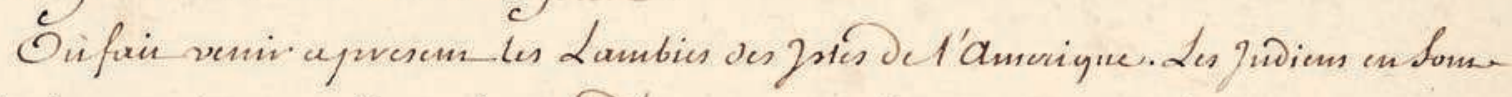

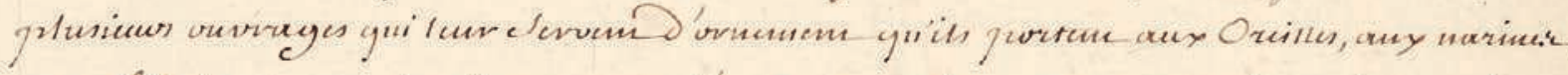

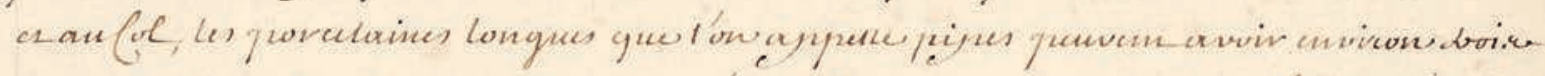

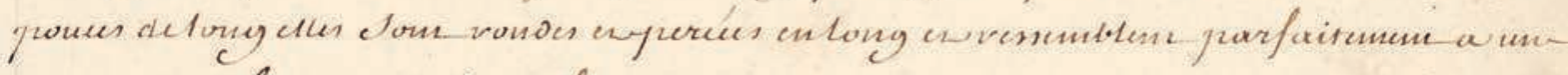

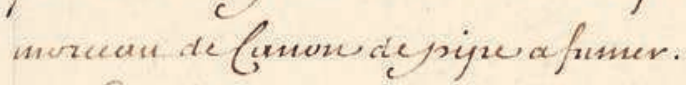

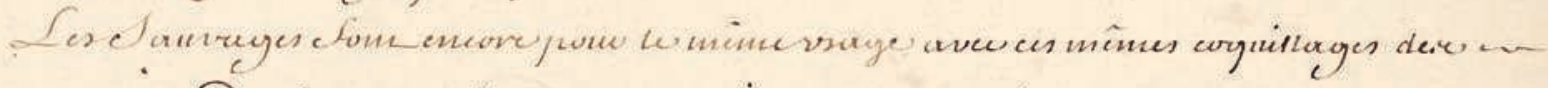

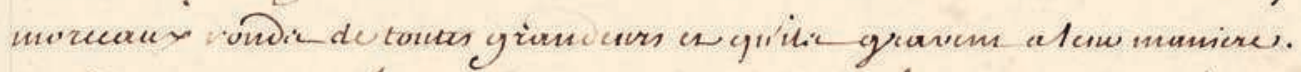

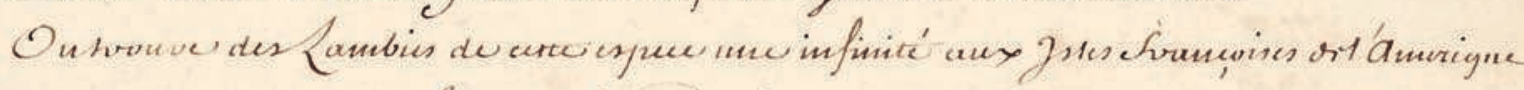

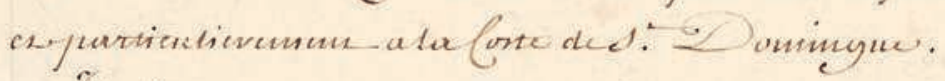

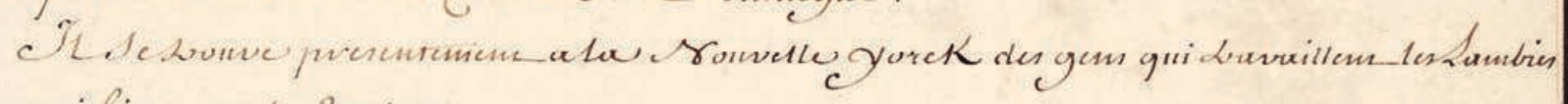
ansibion que les fuvions.

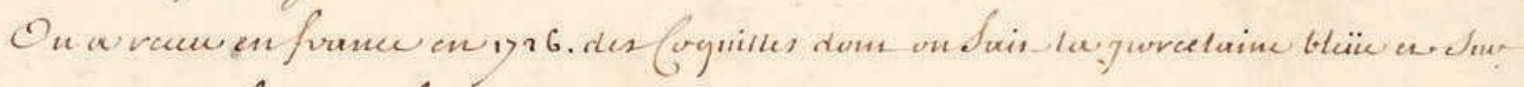

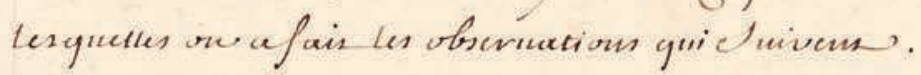

\section{Accscription des Coquillages}

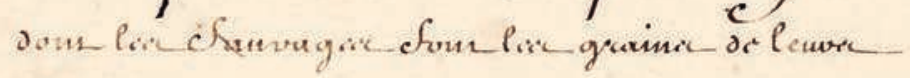
Colicaric .

$2 a$

cour

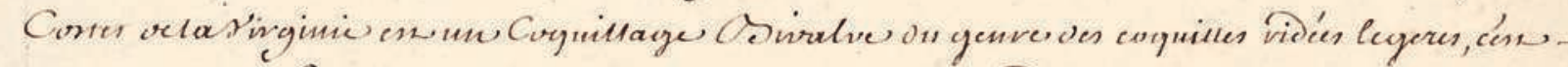

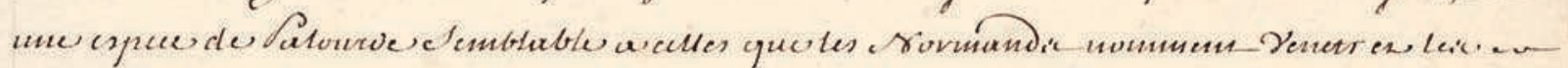
Provenceurue Clonines.

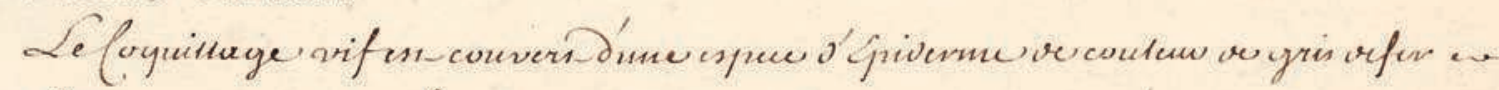

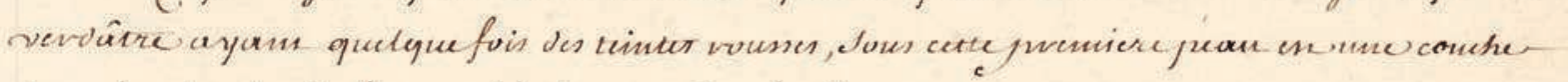

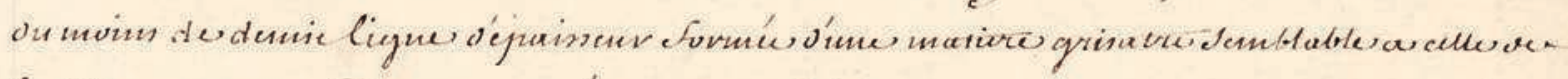

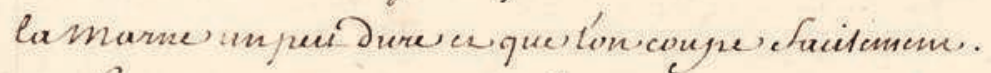

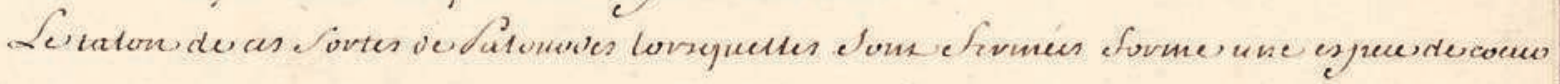

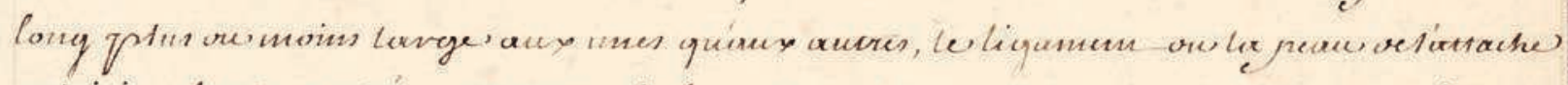

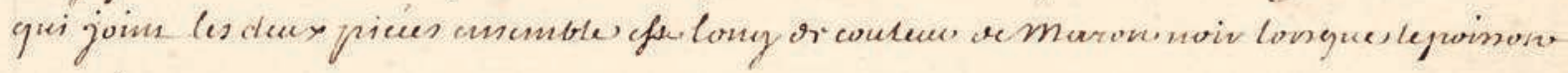
ensivame.

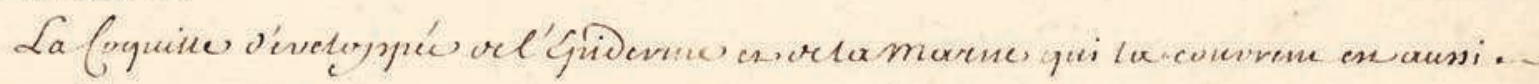

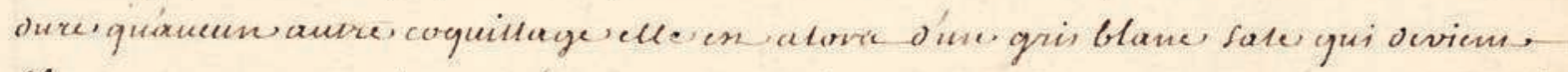

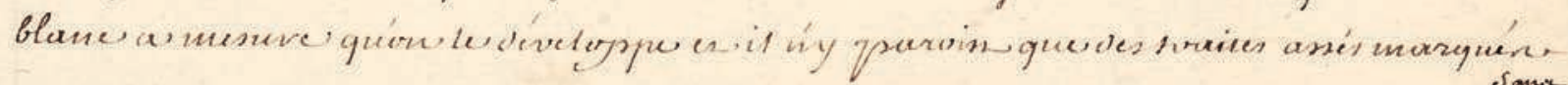


c. Sanir néunmoint crecunes vides.

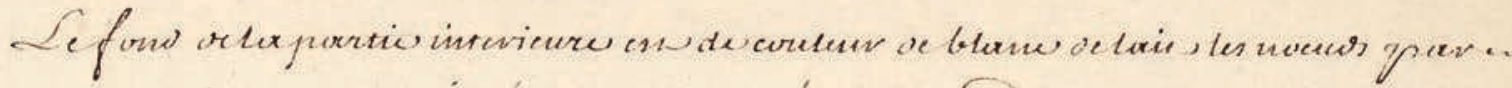

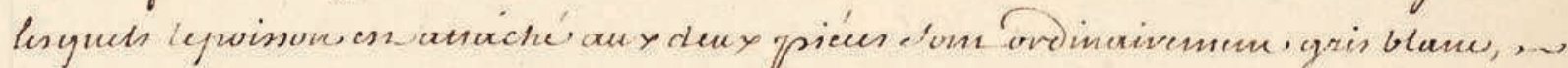

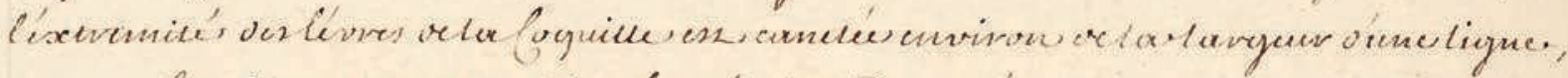

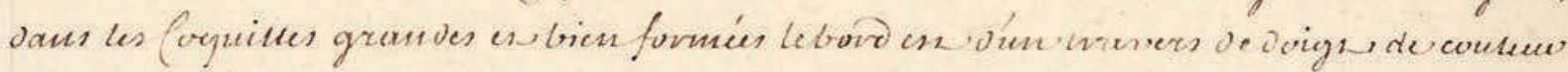

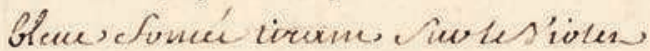

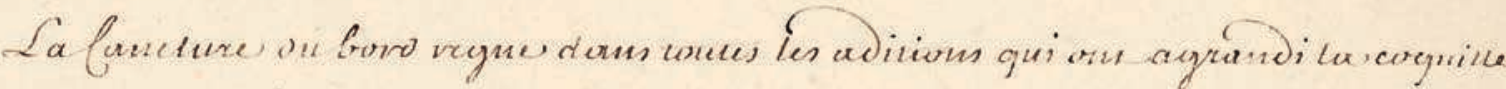
a. mesure qualle a aurymenter.

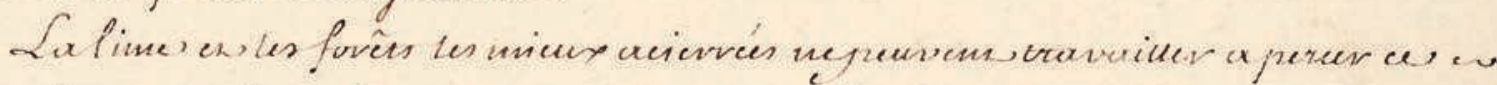

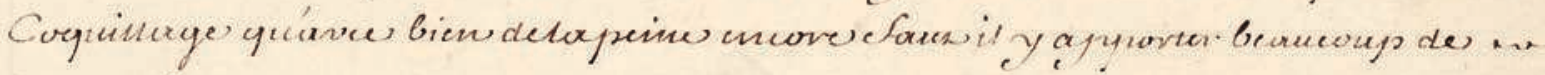
proescution.

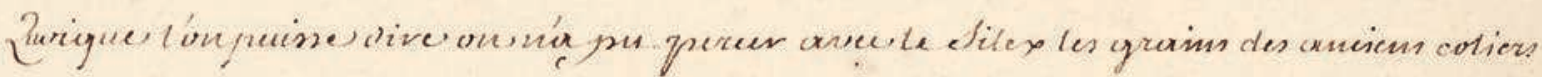

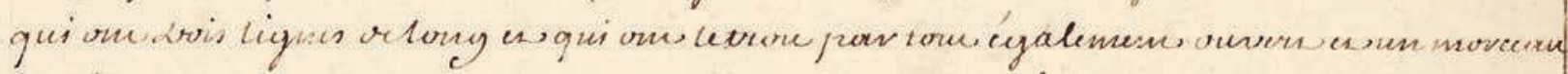

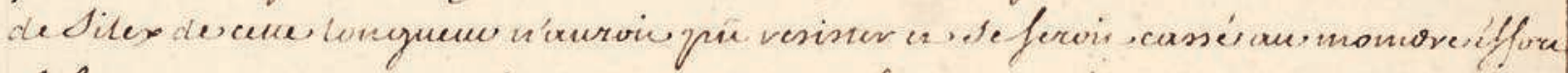

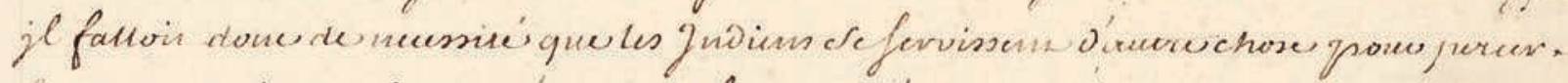

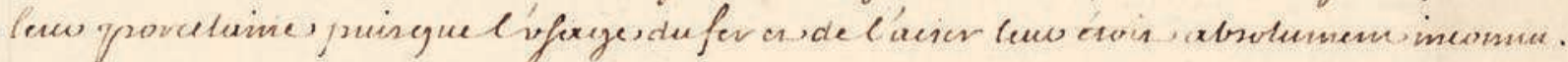

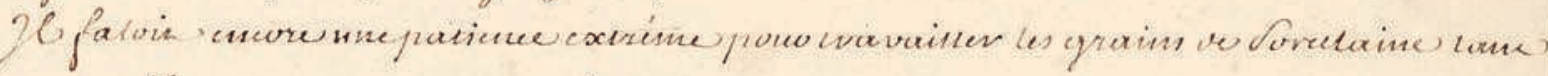

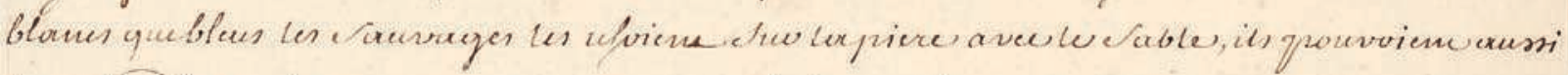

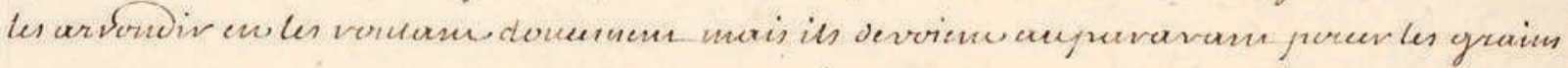

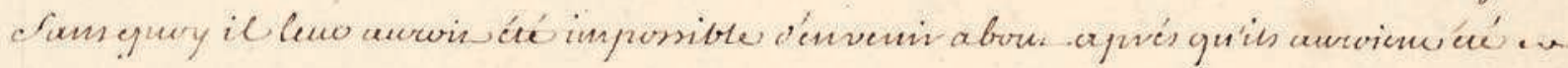
anvowis anplis.

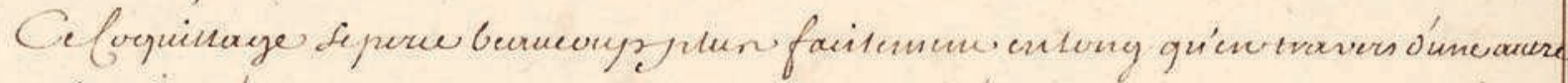

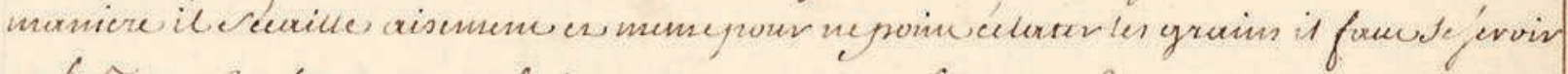

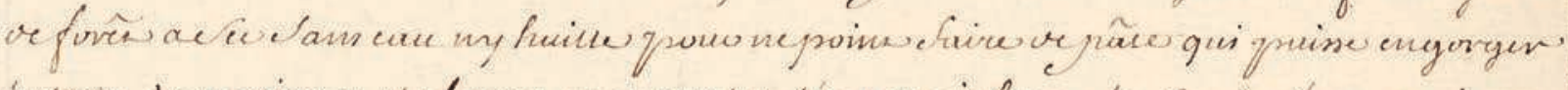

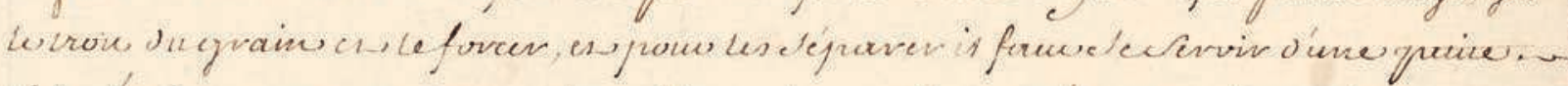

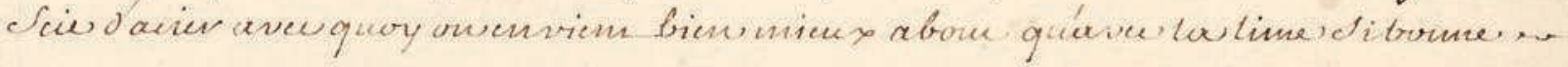
queleymines estre.

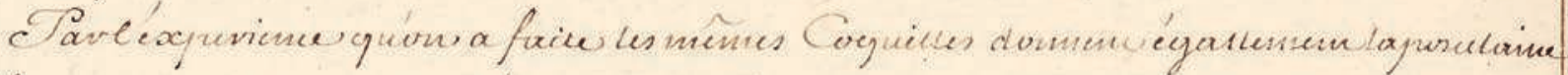

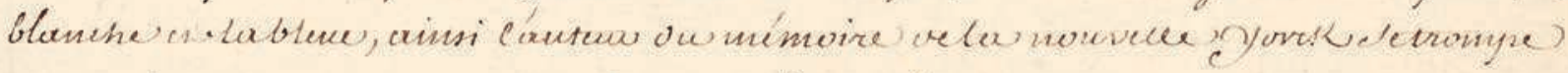

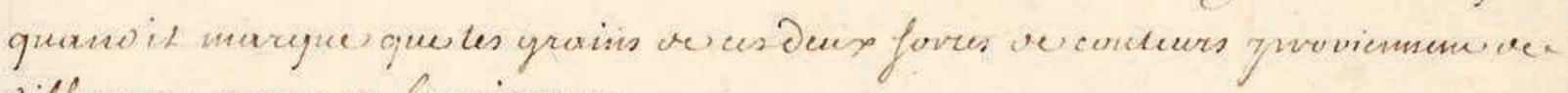

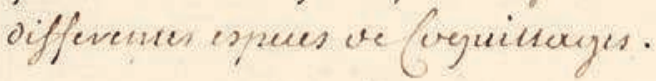

$\mathrm{P}_{\mathrm{x}}$ ?

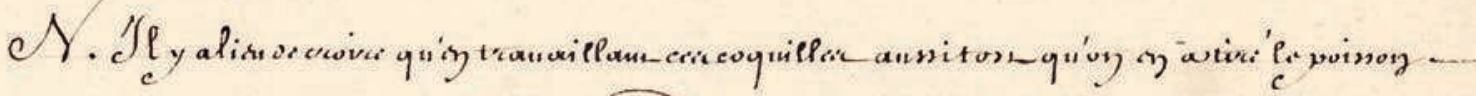

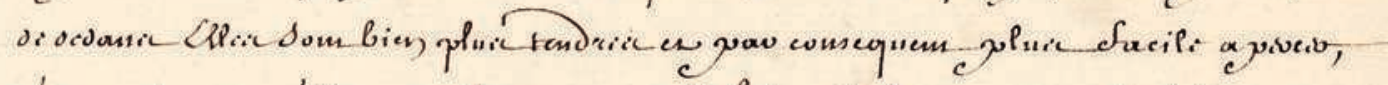

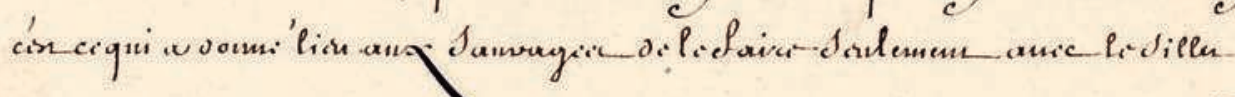


Paroles des Sauvages Iroquois à M. Le Marquis de Beauharnois lorsqu'ils le virent pour la première fois et qu'ils pleurèrent la mort de feu M. le Marquis de Vaudreuil en 1726 à Montréal 


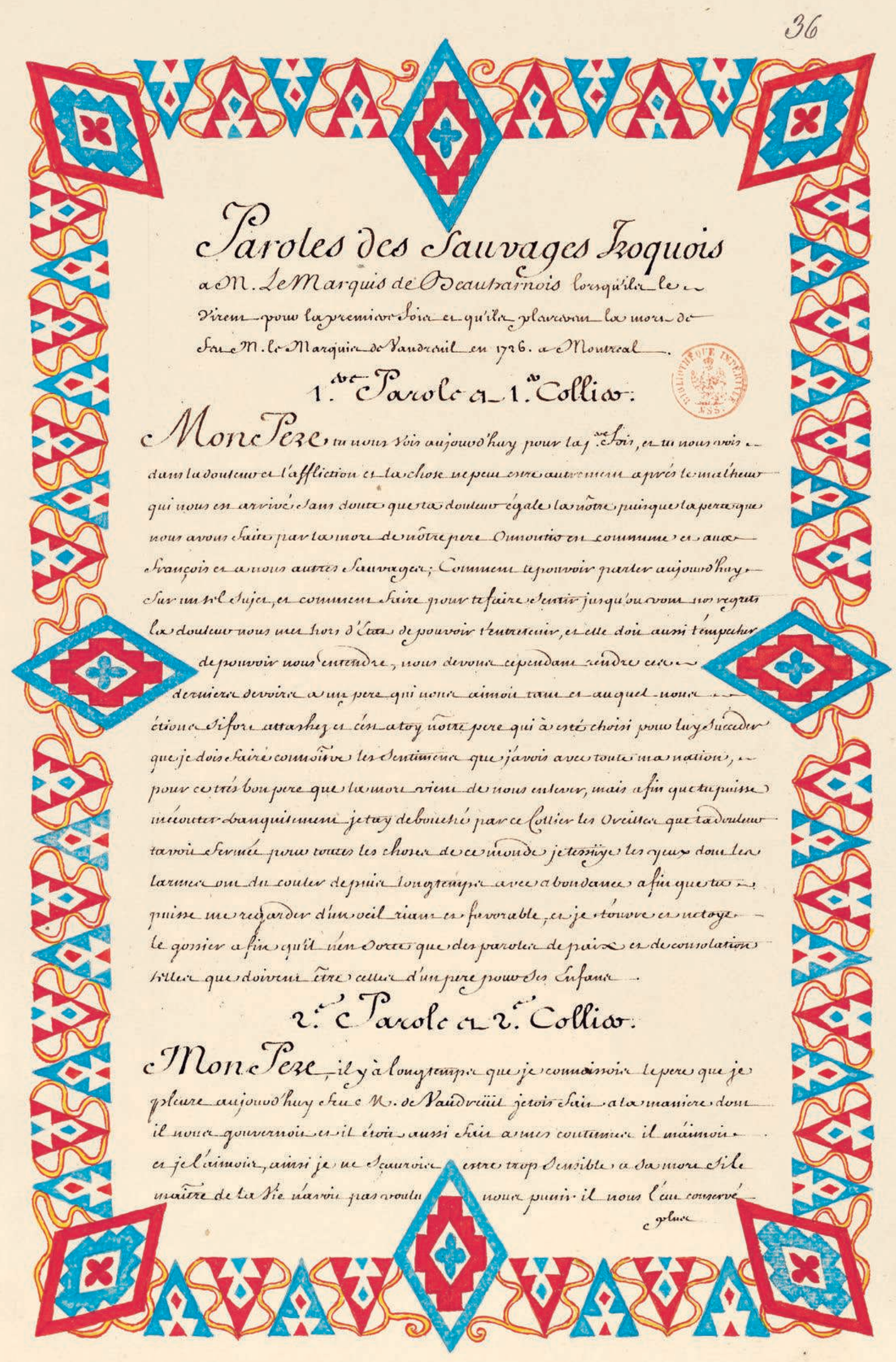




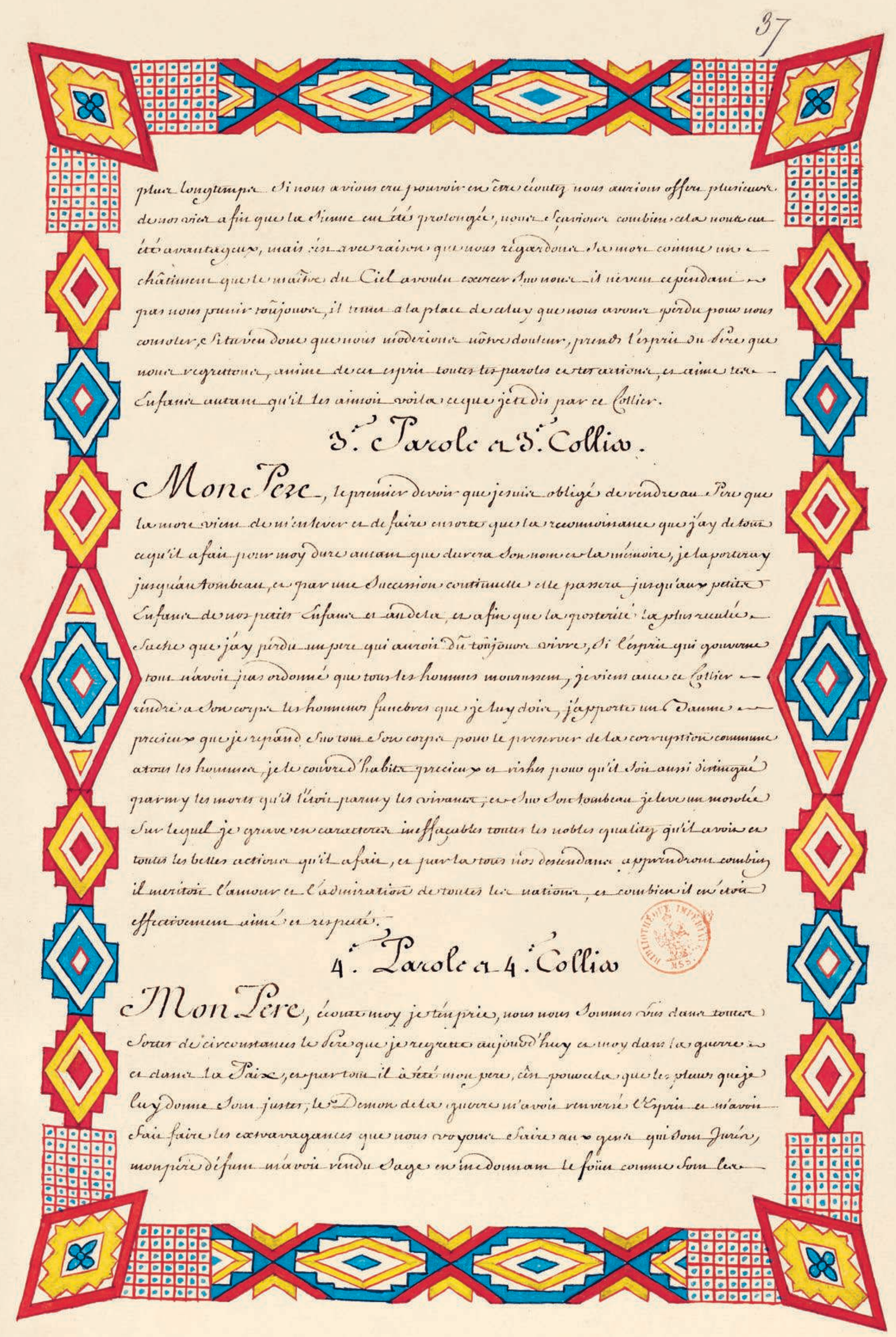




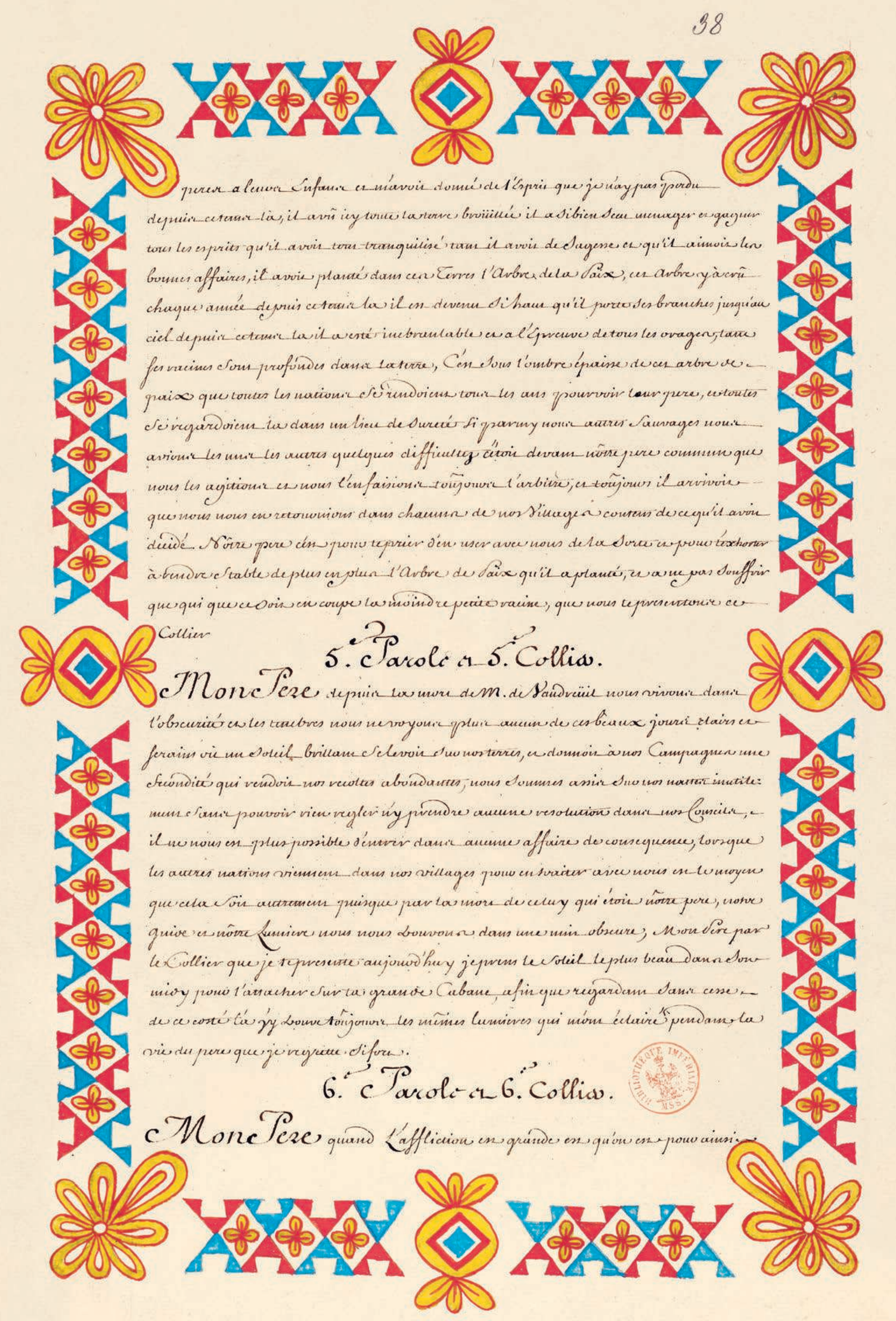




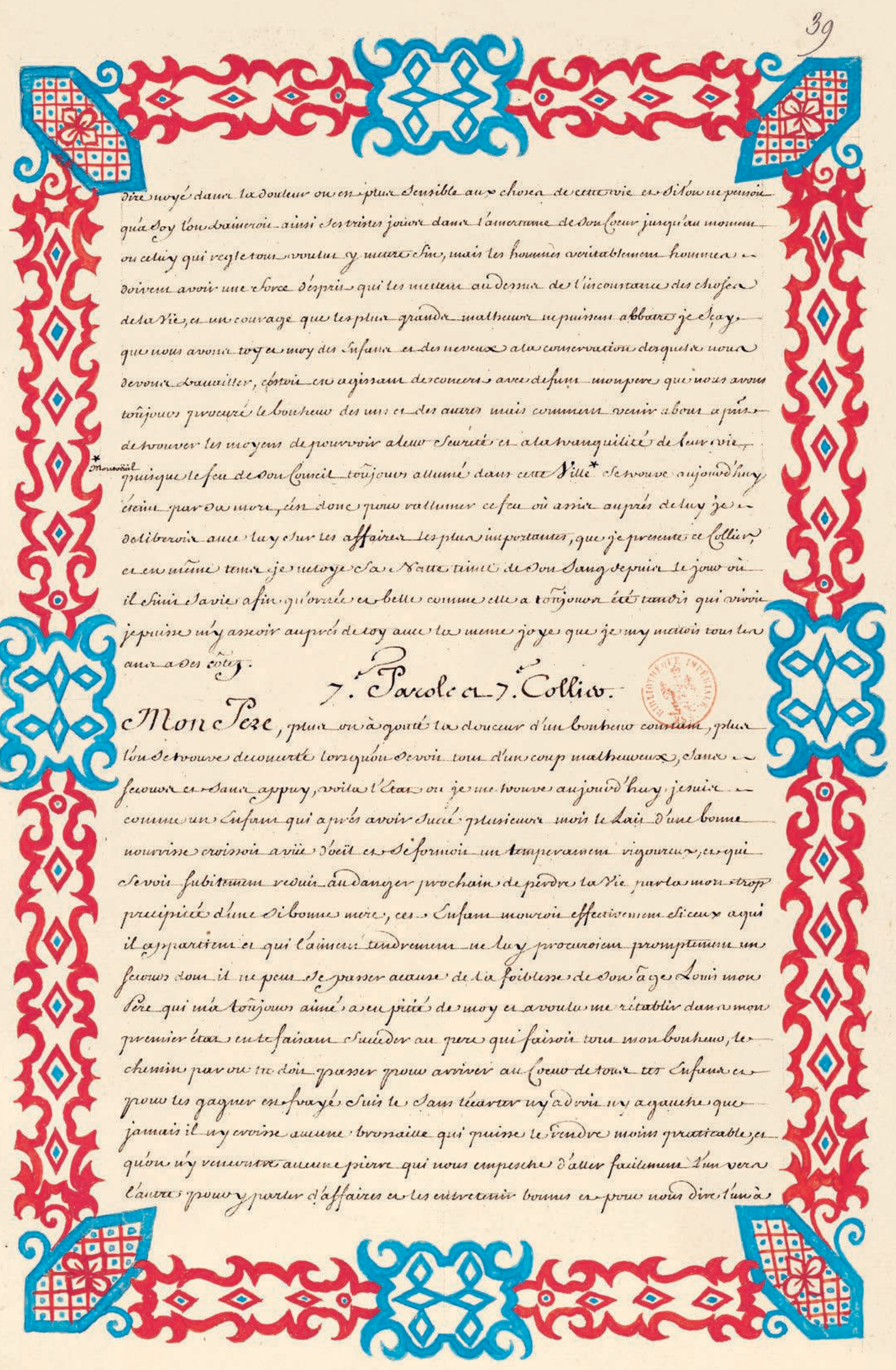




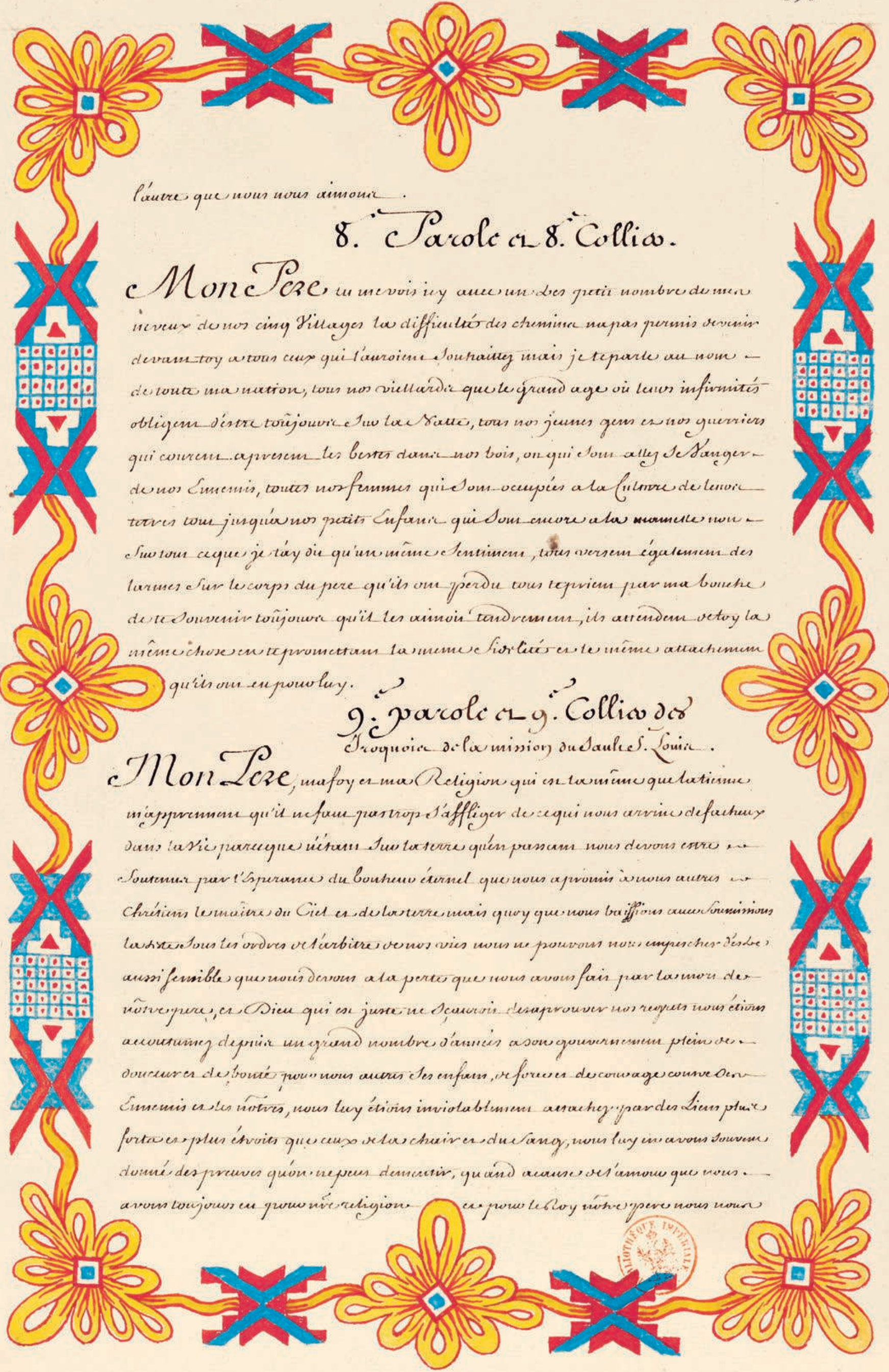




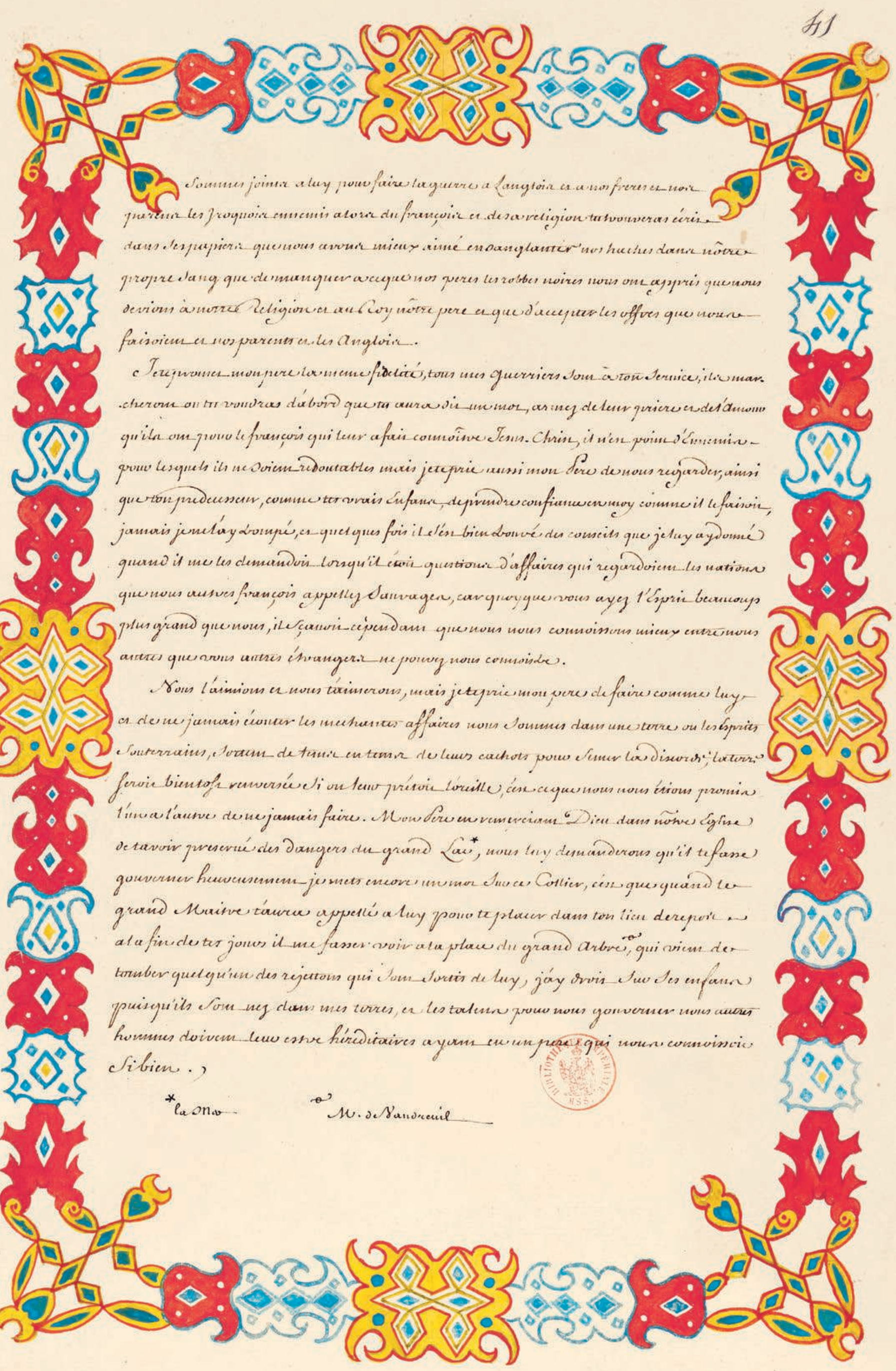

